\title{
THE EFFECT OF STORAGE METHODS ON VIABILITY AND SYMBIOTIC PROPERTIES OF SOYBEAN NODULE BACTERIA
}

\author{
T. M. Kovalevska, D. V. Krutylo, \\ V. P. Horban, I. M. Romanova, T. O. Usmanova
}

During numerous studies conducted by scientists it was established that efficiency of nodule bacteria symbiosis with legumes can be improved via utilizing active and competitive bacterial strains for inoculation. Selection of rhizobia according to the symbiotic activity and warranted maintaining of advantageous strains in collections is an important component of scientific studies aimed at development of the new microbial drugs for legumes.

Due to the increased demand for biological drugs, necessity of the manufacture for keeping cultures of microorganisms viable and stable according all parameters is also increased. Therefore, development of longterm storage methods for advantageous nodule bacteria strains that would provide stability of their productive-valuable properties takes new practical significance [1].

Methods of lyophilization, cryopreservation, periodic reseeding, and keeping under mineral oil layer are mainly utilized in collections for keeping nodule bacteria. Advantage of the two latter strains includes their simplicity, technical availability, as well as possibility for longterm keeping of the microorganisms in metabolically active condition. Disadvantages include the necessity for regular recovery of the cultures that increases the risk for contamination with foreign microflora and development of spontaneous mutations that change collection strains. The most common and effective method of rhizobia long-term storage is lyophilization. According to the data of staff members of the MSU microbiology department [2], strains of pea, clover, medic nodule bacteria remain viable during 33-34 years of storage (number of viable cells was $1 \times 10^{4}-1 \times 10^{7}$ cells per ampoule). At the same time, bacteria expose to severe effect of low temperatures and vacuum during lyophilization that may be accompanied with genetic variations and lose of strain properties.
We initiated study of the long-term storage conditions of advanced nodule bacteria strains in 2006. Considering that the main requirement to rhizobia collections is the guarantee for symbiotic properties preservation, significant attention was paid to the investigation of functional activity of the strains put for the long-term storage.

The objective of this work was to study effect of different storage methods on viability and symbiotic properties of Bradyrhizobium japonicum 46 master seed strain.

Materials and methods. Master seed strain B. japonicum 46 (B-23), which is stored in the collection of useful soil microorganisms of the Institute of Agricultural Microbiology and AgroIndustrial Manufacture of NAAS was used in the work $[3,4]$.

$B$. japonicum 46 strain was isolated in 1995 , and it is maintained in the collection by periodic reseeding method. In 2006 this strain was put for long-term storage under the mineral oil layer and in 2007 in lyophilized dry condition.

For lyophilization B. japonicum 46 culture was cultivated on leguminous (lupine) agar before initiation of the stationary growth phase. Protective sucrose-gelatine medium $(10: 1)$ was used. Lyophilization of bacteria was conducted on the base of D. K. Zabolotnyi Institute of Microbiology and Virusology.

Viable cells count in the samples following lyophilization and 5 and 6 years following storage was measured via critical dilution method by calculation of number of colonies on the surface of leguminous agarized medium.

Culture for maintaining under mineral oil was cultivated on solid and semifluid $(0.3 \%$ agar) leguminous medium to stationary growth phase, primed with sterile mineral oil with layer of $1.5 \mathrm{~cm}$, and stored at room temperature. Bacterial viability was studied by exhaustive seeding method on 4 sectors of the surface of agarized culture medium. Count 
of sectors colonized with bacteria was measured, and culture activity was evaluated by 4-point scale. Following long-term storage, nodule bacteria cultures were renewed by three-time reseeding on the optimal culture medium.

Symbiotic properties and efficiency of B. japonicum 46 strain stored by different methods were studied under conditions of field studies on meadow-chernozemic leached slightly clay-loam soil with the following agrochemical parameters: content of humus in the plow layer (according to Tiurin) $-3.5 \%$, easily hydrolysed nitrogen (according to Kornfield) - $95.0 \mathrm{mg}$, extractable phosphorus $\left(\mathrm{P}_{2} \mathrm{O}_{5}\right)$ (according to Kirsanov) - $251 \mathrm{mg}$, exchangeable calcium $\left(\mathrm{K}_{2} \mathrm{O}\right)$ (according to Kirsanov) - $108 \mathrm{mg}$ per $1 \mathrm{~kg}$ of solid (experimental field of the Institute of Agricultural Microbiology and AgroIndustrial Manufacture of NAAS). Ustia variety of soybean was used in the experiments. Before planting, soybean seeds were treated with suspension of microorganisms assuming 200-300 cells per 1 seed. Area of the accounting site is $5.0 \mathrm{~m}^{2}$, fourfold repeatability.

Initiation of the experiments, sampling, yield accounting were conducted according to the current rules. At the phases of budding, flowering and legumes formation amount of nodules was counted, their weight and nitrogenase activity were determined [5]. Competitiveness (ratio of the number of the formed by strain nodules to total number of the studied nodules from each variant, expressed as percentage) of the B. japonicum 46 strain following long-term storage was evaluated by agglutination reaction.

During the work, antiserums to B. japonicum 46 strain and to three typical representatives of soybean nodule bacteria: B. japonicum M-8, B. japonicum KB11, B. japonicum 6346 were used. Antiserums were obtained by the method described earlier (method of All-Russian Research Institute for Agricultural Microbiology (ARRIAM) in our version) [6].

Activity of the symbiotic nitrogen fixation was determined by acetylenic method [7] on the gas chromatograph "Chrom-4" with flame-ionization detector (column with $\beta$ $\beta$ 'oxydipropionitrile). Thermostat temperature is $500 \mathrm{C}$. Consumption of gases: hydrogen $30 \mathrm{~mL} / \mathrm{min}$, nitrogen $-100 \mathrm{~mL} / \mathrm{min}$, air -500 $\mathrm{mL} / \mathrm{min}$.

Statistical data processing was conducted according to B. O. Dospekhov [8] and using software application Statistica 7.0.

Therefore, summarizing obtained results it can be concluded that for long-term storage of B. japonicum 46 master seed strain all three studied methods can be used. The best is periodic reseeding method and lyophilization which provide high strain viability and stability of its symbiotic properties during long term. Maintaining under mineral oil can be recommended as the additional method providing reseeding of nodule bacteria cultures following every 2-3 years. The methods require further investigation for longer terms of preservation and higher number of nodule bacteria strains. At the same time, established fact of maintaining of B.japonicum 46 strain symbiotic properties in case of long-term in vitro storage suggests usefulness of the above mentioned methods for storage of the advantageous and master seed strains of soybean nodule bacteria. 